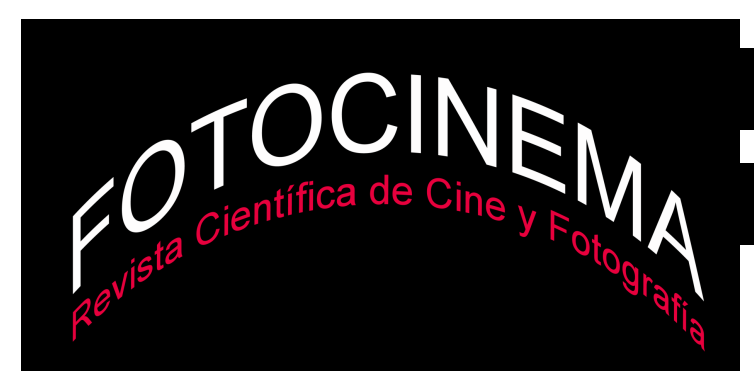

\title{
EL AMOR DE L@S RAR@S. CINE Y HOMOSEXUALIDADES DURANTE LA DÉCADA DE 1980 EN ARGENTINA
}

\author{
QUEER LOVE. \\ ARGENTINIAN FILMS AND HOMOSEXUALITY IN THE EIGHTIES \\ Gustavo Blázquez \\ CONICET-IDH/ FFyH-UNC, Argentina \\ gustavoblazquez3@hotmail.com
}

\section{Resumen:}

Este trabajo se detiene en el análisis de los modelos que permiten imaginar y experimentar relaciones (homo)afectivas a partir de una serie de films argentinos. Específicamente nos interesa describir y comparar imágenes elaboradas en el "destape alfonsinista" de mediados de la década de 1980 relacionadas con encuentros homoeróticos. Las películas consideradas son Adiós Roberto (Enrique Dawi, 1985) y Otra historia de amor (Américo Ortiz de Zárate, 1986) que presentan el amor entre los muchachos y Atrapadas (Aníbal Di Salvo, 1984) Correccional de mujeres (Emilio Vieyra, 1986) y Sucedió en el internado (Emilio Vieyra, 1985) que escenifican relaciones lésbicas. Para acercarnos a esas producciones, que reservan el amor para los varones y ubican a las lesbianas en la cárcel, nos valemos de la noción de "guiones sexuales" elaborada por Gagnon y Simon en sus estudios sobre la conducta sexual. El análisis de esas historias de amor y sexo, cinematográficamente objetivadas, permitirá describir cómo se decían/hacían diferencialmente posiciones de género, eróticas, edad, y clase en esos años.

\begin{abstract}
:
This paper focuses on the analysis of models to imagine and experience (homo)affective relationships in some Argentine films. Specifically we describe and compare images concerning homoerotic encounters made during the "destape" of the mid1980s. The films in question are Adiós Roberto (Enrique Dawi, 1985) and Otra historia de amor (Américo Ortiz de Zárate, 1986) that present the love between men and Atrapadas (Aníbal Di Salvo, 1984), Correcional de mujeres (Emilio Vieyra, 1986) and Sucedió en el internado (Emilio Vieyra, 1985) that portray lesbian relationships. To approach these texts we use the notion of "sexual scripts" developed by Gagnon and Simon in their studies on sexual behavior.

The analysis of these stories of love and sex, cinematically objectified, allow us to describe how gender, eroticism and social class were perfomatively (re)produced in those years. The differences in the ways of doing homosexuality (in)visible demonstrate the complexity and variations of the sexual morality in the post-dictatorship Argentina culture.
\end{abstract}

Palabras claves: afectividad; homosexualidad; lesbianismo; Masculinidad; Feminidad; Sexo.

Key Words: Affectivity; Homosexuality; Lesbianism; Masculinity; Femininity; Sex. 
Cómo citar: Blazquez, G. (2017). "El amor de l@s rar@s. Cine y homosexualidades durante la década de 1980 en Argentina". Fotocinema. Revista científica de cine y fotografía, $\mathrm{n}^{\mathrm{0}}$ 15, pp. 111-137. Disponible: http://www.revistafotocinema.com/

\section{Aquellos años' 80}

La última dictadura cívico-militar en Argentina (1976-1983) encarnó un proyecto empeñado en (re)crear un nuevo orden a partir del exterminio de un “otro" político, personificado en la imagen del "subversivo". En ese contexto se aplicaron políticas de Terrorismo de Estado que pusieron el aparato estatal al servicio de acciones organizadas en un plan sistemático de secuestro, tortura y exterminio de personas, apropiación de niños, robos, extorsiones y expoliación económica. Homosexuales y travestis junto con artistas de vanguardia, del campo popular o asociados con el rock, consumidores de sustancias psicoactivas ilegales, delincuentes comunes, prostitutas, entre otros y otras integraban poblaciones si no "subversivas" al menos "peligrosas”, “dañinas”, y por lo tanto también fueron objeto de represión.

A inicios de la década de 1980, luego de cuatro años en el poder, el gobierno militar ingresó en una fase de "agotamiento" a raíz de una multiplicidad de factores que cristalizaron en una crisis generalizada (sociopolítica y económica). En ese marco, se buscó la reivindicación histórica de recuperar las Islas Malvinas con el objetivo de reconstruir la legitimidad del régimen. La guerra y la posterior derrota fueron los detonantes finales que posibilitaron vislumbrar la reinstitucionalización del país. En octubre de 1983 se llevaron a cabo elecciones libres y Raúl Alfonsín fue electo presidente. Durante los primeros años de su mandato, la sociedad argentina atravesó una "primavera democrática" que posibilitó experimentar un presente e imaginar un futuro menos represor. Se juzgó y condenó a los máximos jerarcas de la dictadura al mismo tiempo que se implementó una reforma educativa, un plan de democratización de la cultura y 
se sancionaron leyes que establecieron la patria potestad compartida y el divorcio vincular.

En esos años del “destape alfonsinista”, y su cita del movimiento cultural posterior a la muerte de Franco en España, se (re)organizó un activismo homosexual. En 1984, junto con algunos amigos, Carlos Jáuregui fundó y se convirtió en el primer presidente de la Comunidad Homosexual Argentina. Ese mismo año apareció abrazado junto con otro hombre en la tapa de un semanario de gran tirada nacional bajo el título "Los riesgos de ser homosexual en Argentina” (Belucci, 2010). Entre esos peligros estaba, como bien recordaron los sujetos entrevistados, la persecución policial, la detención arbitraria y la aparición de la epidemia de Sida.

Durante la década de 1980 se produjeron importantes modificaciones en los dispositivos discursivos que regulaban esas formas de nominación y modos de advenir varón homosexual (Perlongher, 1997; Jaúregui, 1987; Meccia, 2006; 2011). Al modelo erótico "loca- chongo" se sumó el término "gay", palabra de origen anglosajón que distanciaba la experiencia homosexual del lenguaje nacional (Sívori, 2005). Pero también, el origen extranjero del término le otorgaba un cierto carácter distinguido que permitía distinguir a los "gays" de otros homosexuales de los sectores populares: "los maricones" o "locas". Al mismo tiempo, el término gay y su connotación de alegría, fiesta y divertimento retomaba de las "locas” el gusto por la diversión (Blázquez, 2008).

Con el término "gay" se construía también un ideal igualitario que actualizaba los sentidos de la "homosexualidad masculina" y consagraba el amor entre varones, al mismo tiempo que distanciaba a la homosexualidad de cualquier tipo de feminidad o "inversión". "Gay" no significaba necesariamente una masculinidad disminuida ("ser menos hombre") sino que procuraba expresar otra forma de ser varón. El nuevo vocablo tampoco presuponía posiciones fijas en los intercambios sexuales de modo tal que si el binomio "loca-chongo" decía también la relación "pasivo/activo", "gay” se asociaba con una práctica "versátil” o "amplia" donde el sujeto actuaba como agente capaz de penetrar y ser penetrado analmente por un compañero erótico (Sívori, 2005). 
Para dar cuenta de los desplazamientos en las tramas de sentidos que organizaban las prácticas y discursos de y sobre sujetos considerados "raros", en tanto disidentes de la heteronormatividad, emprendimos una investigación sobre las formas y condiciones de la sociabilidad homoerótica a partir de entrevistas con varones y mujeres homosexuales jóvenes en la década de 1980 y que al momento del encuentro superaban los 55 años. Como parte de ese trabajo se incorporó el análisis de bienes culturales consumidos por los entrevistados, principalmente obras cinematográficas, literarias, musicales y otros relacionados con la formación y desarrollo de una escena nocturna organizada a partir de erotismos y (homo)sexualidades (Blázquez \& Lugones, 2014; Reches, 2014).

De acuerdo con las hipótesis de la investigación, los diferentes términos describirían subjetividades posibles y formarían parte de unas narrativas capaces de organizar performativamente cierta "experiencia homosexual" articulando cuestiones vinculadas a diferencias de clase, raza, género y erotismo. Cada forma de nombrar y visibilizar, de decir y de hacer, los vínculos e intercambios homoeróticos sería una imagen, objetivada en bienes culturales, que interpelaba a los sujetos y donde podían reconocerse y desconocerse.

Enmarcado en esas discusiones, este artículo se pregunta por las persistencias y transformaciones de los regímenes de nominación de una cierta experiencia homosexual masculina urbana, juvenil y de camadas medias. Con ese objetivo hace foco en una serie de films argentinos para describir y comparar ciertas imágenes elaboradas durante el “destape alfonsinista” relacionadas con encuentros homoeróticos. Las películas consideradas son Adiós Roberto (Enrique Dawi, 1985) y Otra historia de amor (Américo Ortiz de Zárate, 1986) que presentan como tema central la cuestión del amor entre los muchachos.

Para acercarnos a esos textos audiovisuales nos valemos de la noción de "guiones sexuales" elaborada por Gagnon y Simon (1974) en sus estudios sobre la conducta sexual. Esos guiones, en permanente construcción y sometidos a crítica, especificarían "los quiénes, los qué, los cuándo, los dónde, y los por qué de determinado tipo de actividades" (Gagnon, 1977, p. 6) sin necesariamente determinarlas. Los guiones operarían en tres niveles: el intrapsíquico, el 
interpresonal y el cultural, donde el primero haría referencia a las dinámicas de formación de un self, el segundo a las que animan las relaciones entre diferentes sujetos y el último a las formas simbólicas públicas. ¿Cuáles eran los guiones que representaban y hacían circular esas producciones? ¿Qué homosexualidades y cuáles homosexuales aparecían como (in)deseables? ¿Cómo se realizaban dramática e iterativamente distintas posiciones de género, clase, eróticas y formas de amar?

Luego del análisis de esos nuevos guiones sexuales propuestos por y para varones homosexuales, el artículo vuelve su mirada sobre las mujeres homosexuales. ¿Cómo se representan los amores lésbicos durante el "destape”? ¿Qué guiones organizaban esos (des)encuentros eróticos? Para ello nos acercaremos a tres producciones de la época que escenifican relaciones lésbicas: Atrapadas de 1984 con dirección de Aníbal Di Salvo y dos films dirigidos por Emilio Vieyra, Sucedió en el internado de 1985 y Correccional de Mujeres de 1986.

El análisis de esas cinco producciones cinematográficas, representativas del “destape" argentino y la "primavera alfonsinista”, nos permitirá describir diferentes formas de (in)visibilizar las relaciones y prácticas homosexuales en su articulación con otras formas de la diferencia social como clase, edad y género. Las distintas imágenes que las obras proyectan posibilitarán observar las variaciones de la moral sexual y otras complejidades de la cultura argentina posdictadura.

\section{Hola Roberto}

A diferencia de las producciones de las décadas anteriores, Adiós Roberto y Otra historia de amor convirtieron a homosexuales masculinos en protagonistas principales y motivo de la historia contada. Por primera vez en la historia del cine nacional, las vivencias de unos personajes homosexuales se transformaron en el eje de la historia y se presentaba en la pantalla el drama del amor que no se atrevía a decir su nombre (Melo, 2008; Olivera, 2012). 
En la producción de Dawi, Roberto (Carlos Calvo), recientemente separado de su mujer, inicia una relación erótico-afectica con Marcelo (Víctor Laplace) a quien como afirma en el film "no le gustan las mujeres". En Otra historia de amor, Raúl Lovera (Arturo Bonin) casado y padre de familia acaba seducido y en los brazos de su compañero de trabajo: Jorge Castro (Mario Pasik). Ambos films están igualmente estructurados a partir de la relación entre un personaje homosexual que sabe de sí y su deseo erótico, aunque no necesariamente pueda enunciarlo, y un personaje que mantiene una relación heterosexual aunque poco feliz que "descubre" su deseo homosexual a partir de la atracción por un sujeto particular.

Ese descubrimiento no se produce en escenarios como la calle, los baños públicos, las discotecas que por esos años se abrieron en ciudades como Buenos Aires o Córdoba, asociados con la homosexualidad y la "mala vida”. Por el contrario, el encuentro del sujeto con su verdad se produjo en espacios moralmente menos sospechosos como la casa o la oficina. El saber sobre sí no se produjo a partir de un cuestionamiento previo o una "sospecha” propia o ajena sobre la heterosexualidad. Tanto Roberto como Raúl se "descubren” a partir del encuentro casual entre los protagonistas. En las dos producciones la relación erótica entre los protagonistas rápidamente se tiñe de amor. El vínculo homosexual es subsumido en la conyugalidad y se establecen comparaciones con relaciones heterosexuales.

Esas producciones no sólo innovaron al presentar historias de amor homosexual y odio homofóbico. A diferencia de los personajes homosexuales de las producciones de décadas anteriores, los films de Dawi y Ortiz de Zárate pusieron en escena a varones homosexuales cuyas performances de género eran coherentes con el género atribuido. No sólo los “nuevos” homosexuales como Roberto y Raúl, eran masculinos. Quienes ya sabían de su homosexualidad, Marcelo y Jorge, no eran afeminados, aunque para algunos pudieran resultar un poco "raros"/"raritos".

En el contexto de una fuerte revisión de las normas morales y prácticas sexuales heredadas de la última dictadura, unos artistas, con alguna trayectoria en el campo cinematográfico y teatral, contaban en un lenguaje melodramático ya 
conocido, otra historia. En este sentido ambos films pueden considerase parte de las poéticas/políticas de visibilización de las homosexualidades masculinas en la Argentina de la época.

Para describir cuáles eran esas homosexualidad (in)visibles/(in)vivibles nos concentramos en las formas de auto y heteronominación de los sujetos homosexuales a las que consideramos como "símbolos dominantes" (Turner, 1974) que organizaban los rituales de interacción. Estas primeras descripciones deberán complejizarse a la luz de un mayor y mejor análisis de los elementos cinematográficos que constituyen los modos en que esas películas ponían en escena la (homo)sexualidad (Williams, 2008) . Su análisis permitirá describir las "estructuras de significación" (Geertz, 1987) o "paradigmas raigales" (Turner, 1974) que ensamblaban performativamente los guiones sexuales culturales (re)presentados en los films.

Adiós Roberto comienza con un primer plano de un joven en el proceso de despertar entre sábanas. El sonido es ambiente. A medida que recobra la conciencia el plano se expande hasta que descubrimos que no está sólo en la cama. El protagonista parece llegar a esa conclusión al mismo tiempo que el espectador. La cámara se fija en él, en su expresión de asombro, sus ojos que se agrandan, la mano que recorre la cara preocupada y luego el torso desnudo. Se incorpora. El plano se agranda, vemos su ropa interior, su cuerpo velludo, magro. Un plano americano muestra su reflejo en el espejo donde se mira no sin ciero asombro. Sale del cuadro y la cámara se vuelve hacia la cama donde vemos dormir plácidamente a otro varón. Esos primeros 100 segundos hacen saber que algún tipo de acto íntimo ocurrió entre esos jóvenes.

En el film no se menciona el término "gay" y homosexual sólo aparece en una página de diario de una escena donde se lee: "Otro homosexual asesinado". En cambio otros vocablos como trolo, marica, maricón, mariconadas, tropos como "darse vuelta", "pasarse al otro bando" y enunciados como "creía que de grande ibas a ser Gardel y mirá: Tita Merello" formaban parte de los lenguajes de odio utilizados por diferentes personajes homofóbicos. Esos personajes formaban parte del elenco (no solo) imaginario que envolvía a Roberto como el amigo de la juventud, la esposa, la prostituta que lo hizo debutar, un antiguo represor y 
asesino, todos ellos relacionados con el barrio que lo vio crecer y que él abandonó.

A través de esos términos y formas de decir al sujeto homosexual se actualizaba la figura histórica del invertido y se (re)hacía de él un ser moralmente despreciable, digno de ser físicamente eliminado, fácilmente reconocible por sus performances afeminadas y que gozaba de ser penetrado analmente. “Te estás clavando un trolo" le pregunta el amigo del barrio a Roberto quien dice: "No lo digas así. Suena como un calificativo”. "Y que querés que sea, ¿un verbo?” le responde enfáticamente su amigo. Esa era la opción que prefería Roberto quien no se reconocía en una identidad sino en una práctica. "Me pasa que estoy teniendo una relación homosexual", dice en el consultorio del analista.

Marcelo tampoco se nombra a partir de una identidad sino que, interpelado por Roberto, lo hace a partir de su (no) deseo. “¿No te gustan las mujeres?” pregunta Roberto a lo cual, ofuscado, responde: "No. No me gustan las mujeres, Ahora ya lo sabés, me conoces un poco más". Las formas de nombrar a los homosexuales cambiaban de acuerdo a los contextos y a quien enunciaba. En el mundo culto de Marcelo no se nombraba a la homosexualidad mientras que en las fantasías terroríficas de Roberto se realizaba con fuerza la nominación homofóbica.

En Otra historia de amor, que también comienza con un primer plano de un joven despertando, pero esta vez sólo y preparándose para ir a trabajar, tampoco se utiliza el término "gay”. Sólo en una escena de intenso dramatismo, en que la esposa de Raúl encuentra a su marido y el amante en el departamento que comparten, se escucha la palabra puto. "Putos de mierda" grita, entre lágrimas, Matilde y le da un cachetazo a Jorge. El término utilizado a lo largo del film es homosexual. Estos usos se encuentran tanto entre quienes condenaban las prácticas homoeróticas como de Jorge, quien afirma en las primeras escenas: "definirme como homosexual sería limitarme. Si hay algo que odio es limitarme (...) El sexo ofrece mil posibilidades. A mí me interesan casi todas”. 


\section{3. "Raro como encendido"}

En la dinámica entre guiones sexuales culturales homofóbicos y sujetos que no se reconocían en los estereotipos ofrecidos, "No soy marica, sin embargo estoy bien con él” afirmaba Roberto frente al psicólogo, aparece un término que merece un mayor análisis: "raro".

Ese término no sólo describía a un sujeto cuyas prácticas y estilo de vida se distanciaban de la norma hegemónica. También y dependiendo fuertemente de las formas de enunciación y más aún cuando se utilizaba el diminutivo "rarito", esos términos resultaban un modo velado, menos vulgar que trolo o maricón, de nombrar a los homosexuales. La ambigüedad del término y los usos estratégicos que posibilitaba puede observarse en una conversación que mantiene Roberto con el compañero de trabajo que le presentó a Marcelo. “¿Vos lo conocés bien?” pregunta Roberto. “Claro, es mi primo, ¿no?”, responde su interlocutor. "No sé. Me pareció un poco raro” continúa Roberto. “¿Raro en qué sentido?”. "Raro” responde Roberto con gestos que dan a entender cierta sospecha de homosexualidad. "iQue te pasa loco! Es un tipo fenómeno que tiene problemas de guita como cualquier otro [y por eso se ve forzado a alquilar un cuarto de su departamento]" contesta enojado el primo quien continúa: "Qué es eso de que es raro. Es un tipo fino, culto, delicado, criado de otra manera de cómo te criaron a vos. Vos naciste en el barrio. iCreciste en el barrio! ¿Que querés que hable igual que vos?”. Con el objetivo de mantener su "cara” (Goffman, 1970), Roberto ataca con un: "Ah claro, vos sos Borges!". "No. No soy Borges pero tampoco ando diciendo por ahí que porque un tipo es educado, culto, es medio rarito" responde enfáticamente su interlocutor.

Roberto carece de los capitales sociales, culturales, y económicos que posee Marcelo, un escritor "con talento" pero sin éxito comercial que participa en el mundo de las artes y vive en un elegante departamento céntrico heredado de su madre. Esos capitales, especialmente los culturales, facilitan que la familia de Marcelo no lo vea como homosexual. Antes que "raro" él es "fino, culto, trabajador" según lo define su primo. Confundir el "buen gusto" con "inversión sexual" aparece como un índice de la falta de cultura y del origen barrial, suburbano, de Roberto. Su posición subalterna provocaría y al mismo tiempo se 
revelaría en esa "falta de clase". Al ver a Marcelo como "raro", Roberto conserva, y reafirma su posición heterosexual aunque pierde la posibilidad de consagrarse en términos de clase social.

La ambigüedad semántica del término raro que le permitía designar a un varón heterosexual de gustos refinados, un poco snob o bohemio, tanto como a un varón homosexual se fundaría en la coalescencia entre un paradigma clasista que reservaba el comportamiento refinado a las clases favorecidas y un paradigma homofóbico que hacía de la sensibilidad artística una característica femenina y por lo tanto presente en los invertidos sexuales. "Raro" y "rarito" permitían simultáneamente nombrar la homosexualidad sin nombrarla pero también invisibilizarla tras la máscara del "buen gusto" y un habitus de clase que borroneaba las prácticas (homo)eróticas. Por ejemplo, Marcelo recibe por primera vez a Roberto ataviado con una bata de seda roja y lo invita a sentarse en unos almohadones “orientales” mientras se escucha música clásica.

Por ello, entre esos usos clasistas y homófobos, con una fuerte vocación normalizadora, algunos varones homosexuales como Marcelo encontraron en el vocablo un refugio de la violencia homófoba y al mismo tiempo una poética para la construcción de una representación de sí superior en términos de clase. La nueva homosexualidad legítima que propone Adiós Roberto aparece ligada a una posición de clase dominante. Esa representación al mismo tiempo que autoriza ciertas performances consideradas un tanto afeminadas o "raras", hace de dichas performances un indicador de clase. Las prácticas homoeróticas en los sectores populares, menos elegantes e interesados por las Bellas Artes, no será problematizado en el cine nacional hasta mucho tiempo después con el film Vil romance (José Celestino Campusano, 2008).

\section{Historia/histeria}

Aunque ficcionales, ambas películas buscaron construirse y fueron recibidas como testimoniales en tanto daban cuenta de conflictos, dudas, alegrías y sufrimientos, de personajes actuales, ciudadanos comunes, adultos jóvenes de camadas medias, que compartían muchas propiedades sociales con el público al 
que estaban dirigidas. En ellas se proyectaban vidas de homosexuales al mismo tiempo que ofrecían un espacio para la proyección de las vidas de públicos que, como los protagonistas de las películas, ya sabían de su homosexualidad o que comenzaban a "descubrirla".

Algunas noches, y como parte de la etnografía, invité a ciertos entrevistados a ver esas películas. Ellos las conocieron en el momento de su estreno en Córdoba cuando eran jóvenes universitarios o se iniciaban en una carrera artística y recordaban que duraron poco tiempo en cartel además de que se entraba al cine con cierta vergüenza: "Era medio como deschavarte", es decir visibilizar la propia homosexualidad. Según sus palabras, los films constituyeron una importante referencia para sus vidas y fantasías. "Era verse ahí". "No sé. A mí me ayudó" "Me pasaba lo mismo [que a Roberto] ... soñaba con el cura y tenía todo eso del pecado metido.. por los curas.. era difícil. No tenías modelos ...” fueron algunas de las frases que aparecieron durante la proyección.

Si bien la dimensión intrapsíquica de los guiones sexuales es imposible de analizar a partir de las producciones cinematográficas, esos films podrían considerarse como objetivaciones culturales de ciertos guiones intrapsíquicos. Con escenas de tintes surrealistas, personajes hiperbólicos, maquillajes dramáticos, escenografías fantásticas, Dawi presenta las fantasías alucinatorias y sueños de Roberto. A lo largo del film se da cuentan de cómo, en la construcción del self, el deseo (homo)erótico se enfrenta con los mandatos sociales. De acuerdo con el protagonista su problema no era su erotismo sino la valoración social de sus prácticas y deseos. El amigo, el padre, la madre, la primera novia, el cura, la prostituta, el asesino o "mano de obra desocupada" de la última dictadura, aparecen como encarnaciones de la homofobia que atacan verbal y físicamente al personaje hasta enloquecerlo.

Roberto, agobiado y confundido por sus fantasmas, huye corriendo en calzoncillos por las calles de la ciudad nocturna. Agentes de la Policía Federal lo detienen. El principio de realidad se impone por la fuerza y recurre a Marcelo para que lo libere. Marcelo honra el pedido pero también involucra a la esposa de Roberto. El film concluye con una toma aérea donde vemos a Roberto 
abrazado a su hijo ubicado a una distancia equivalente de Marta y de Marcelo sin saber qué camino tomaron los protagonistas

De un modo menos espectacular Dawi también presenta los guiones intrapsíquicos que ordenaban la subjetividad de Marcelo, quien no estaba atormentado por "descubrirse" en una relación homosexual sino por sus estrategias afectivas. En una escena de alto contenido dramático, Roberto, atormentado por sus fantasmas, le comunica a Marcelo que decide irse de la casa. Un plano medio muestra el diálogo del que Marcelo parece estar ausente hasta que reacciona, y en primer plano le cuenta al amante sus penurias: la pérdida de su padre a temprana edad, la relación con su hermano "normal", la madre, y plantea como él siempre tuvo que "comprender". Esa posición afectiva, basada en la represión de sus sentimientos y la veladura de su emocionalidad erótica, le aseguró su supervivencia aunque no le permitió que alguien lo “comprendiera” a él. Su primo, obnubilado por el brillo culto de Marcelo, ni siquiera podía verlo como "rarito". Pareciera que solo su amiga lesbiana y agente literario, Alejandra, lo comprendiera cuando, por ejemplo, en una escena posterior hablan de la vejez y fantasean con un posible casamiento. Él descarta la opción porque ella "tendría otras mujeres". Es en ese momento de profunda intimidad, de confianza y bienestar compartido con su amiga lesbiana, cuando se da la inversión del género en el lenguaje y Marcelo se dice "mujer” y juega con el estereotipo del invertido.

Antes que proponer la resolución de los conflictos intrapsíquicos a partir de la intervención colectiva sobre los dispositivos y discursos homofóbicos, Adiós Roberto proponía una solución psicológica. La historia se hace histeria, le recuerda el psicólogo a Roberto antes de ofrecerle la solución a su malestar: "el secreto de todo está en que elijas una forma de vida que te haga feliz".

En Otra historia de amor esos conflictos no ocupan un lugar tan preponderante en la trama. Aunque sabemos del sufrimiento de los protagonistas, de sus sentimientos amorosos, de la culpa que experimenta Raúl y, principalmente, de cómo los deseos y sueños juveniles fueron traicionados con el correr de los años, la producción de Ortiz de Zárate confía menos en una solución individual para esos malestares. En el film se deja adivinar cierta noción de "derechos 
humanos" como cuando Jorge, quien hacía terapia de grupo, se enfrenta al directorio de la empresa que decidió rescindir su contrato. A los gritos les dice: "Soy una persona y todavía tengo el derecho a vivir, a sentir, a elegir”. En la misma dirección, la excéntrica tía de Raúl, sexagenaria viuda de un militar que teje tapices y enloquece con Nina Hagen, le dice a su sobrino: “A esta vieja bruja no le gusta dar consejos pero te voy a decir algo: defendé tus cosas por más locas que parezcan porque si vos no las defendés no te las defiende nadie”.

\section{La misma historia de amor}

Además de modelizar los guiones intrapsíquicos, los films ofrecían también una representación de guiones interpersonales que podemos describir a partir de la escena de seducción que concluye con la primera relación sexual y del modelo de relación erótico-afectiva propuesto.

Ambas producciones desmienten cierta opinión del sentido común homofóbico según la cual varones heterosexuales, especialmente jóvenes, estarían expuestos a la peligrosa seducción de un "degenerado" de mayor edad que podría pervertirlos y hacerlos "cambiar de bando" o "darse vuelta". En esos films no hay perverso y pervertido, víctima y victimario, no hay engaño ni trampas. Si bien en Adiós Roberto el alcohol aparece como habilitador, las propias palabras del protagonista: “Juro que no hubo violación. Fue por pura voluntad”, se encargan de desmentir el mito de Ganimedes.

Luego de un vernissage donde Roberto se emborracha, actúa sin distinción y se declara "subcultural" en medio de una ambiente "cultural”, ambos amigos llegan al departamento. La intoxicación alcohólica parece autorizar contactos corporales más íntimos. Bamboleándose, va hacia su dormitorio, se tiende sobre la cama, y le pide a Marcelo que lo desvista. Su amigo comienza a desnudarlo. Le afloja la corbata, le desprende los botones de la camisa, le acaricia el vientre, los pectorales y el cuello. Roberto lo detiene, le toma la mano y le dice: "Quedate a dormir". "Estas borracho" le responde su amigo, a lo que contesta "No todo lo que parece". 
La escena se construye a partir del montaje de primeros planos del rostro de Marcelo encendiéndose de placer y de sus manos recorriendo el cuerpo velludo de su amigo mientras se escuchan las risas de Roberto. Dawi no muestra la relación sexual subsiguiente. Sólo presenta este preámbulo, como parte del relato que Roberto le hace a un psicoanalista, y la mañana siguiente con la que se inicia el film. Una elipsis de contenido cubre lo que ocurrió entre las sábanas. A diferencia de Adiós Roberto, en Otra historia de amor vemos primeros planos de caricias entre hombres, planos medios de varones quitándose la ropa o tendidos en una cama, y planos generales de cuerpos masculinos desnudos. Toda una imaginería homoerótica se desplegaba en la producción de Ortiz de Zárate.

Mucho más audaz, el film introdujo escenas que mostraban, como parte de un melodrama, prácticas eróticas. Con una cámara fija, en posición frontal y en un plano medio, presenta una relación heterosexual según la posición conocida como misionero. Sobre una mujer que poco parecía disfrutar e involucrarse en el juego se movía un varón cuyo rostro no podemos ver. Inmediatamente después de eyacular él gira hacia el lugar del espectador y en primer plano vemos el rostro de Raúl que expresa cómo el goce no le produjo satisfacción alguna. Mientras tanto, vemos cómo ella abandona el lecho.

Como parte de ese retrato de las prácticas sexuales de la época, Otra historia de amor muestra a dos secretarias de la oficina donde trabajaban Jorge y Raúl, instruyéndose, a partir de una revista, sobre las técnicas para practicarle sexo oral a un varón y presenta los juegos de seducción entre los protagonistas. "Usted me gusta... me gustaría acostarme con Usted”, encara Jorge a su jefe en unas de las primeras escenas del film. Ese arrojo masculino se repite cuando posteriormente le entrega una nota, firmada por "El Zorro", que dice: "si sos guapo y te animás te espero en...”, seguido de una dirección y horario. Un plano general muestra a Raúl, de espaldas y leyendo la nota mientras orinaba. Sosteniendo su pene con una mano, exclamó: “hijo de puta”. Interpelado en su honra, Raúl acepta el desafío y se presenta a la cita. Aquí no habrá intoxicación que justifique como poco a poco el secretario desviste a su jefe sino un intercambio explícito y consciente de palabras, miradas y acciones que culmina 
en una, no muy exitosa, relación sexual. Confundido, o "rallado" como se autodefine, será Raúl quien proponga un segundo y feliz encuentro.

Ortiz de Zárate construyó esa escena de sexo homosexual, de casi dos minutos de duración, a partir del montaje de primeros planos de partes de los cuerpos de los amantes en contacto (manos que se entrelazan, dedos que rozan espaldas o pectorales, bigotes sobre una nuca o un ombligo velludo), de planos detalles donde se pierde la referencia a la parte del cuerpo retratada y al sexo de los participantes, y de planos medios y generales que restituían la identidad sexogénerica de los personajes.

A diferencia de la anterior relación heterosexual que muestra el film, en este encuentro homosexual no se representa la descarga seminal. El orgasmo entre varones, y acciones de mayor intimidad como besos, lamidas, juegos con los genitales, son suprimidas. Por el contrario, la inmediata separación de los amantes después del clímax en la escena heterosexual deviene en una especie de placer continuo. La secuencia que narra el encuentro sexual de Jorge y Raúl concluye en un plano general que los muestra, a contraluz, desnudos y con sus cuerpos entrelazados. Uno de ellos fuma un cigarrillo.

La dimensión extática, fuera de lo cotidiano, excepcional, de esa relación homosexual, se complementaba con el sonido. Distinguiéndose abruptamente de la escena anterior y de la siguiente con sonido ambiente, la secuencia que narra el encuentro gozoso entre los amantes se editó con una música melodiosa y romántica con instrumentos de viento, cuerdas y percusión.

Aunque de manera diferente, ambos films presentaron y enfatizaron la agencia de varones, como Roberto y Raúl quienes, "heterosexuales” y padres de familia eligieron voluntariamente mantener relaciones sexuales con otro varón. Si bien los protagonistas principales, a los ojos del mundo social, devienen homosexuales, para ellos el conflicto no se jugaba en la oposición/opción homosexual/heterosexual. "El hecho de que yo tenga una relación con Castro, no significa que no te quiera" trataba de explicarle Raúl a su dolida esposa. El drama no consistía tanto en descubrir un deseo por otros varones sino en el placer de amar a un sujeto con quien se compartía una misma anatomía, identidad y performances de género. 
El sexo con otros varones no aparecía como imposible/impensable. Jorge, por ejemplo hablaba de prácticas como la masturbación colectiva y otros ejercicios homoeróticos adolescentes. Lo nuevo e (im)posible era el amor homosexual y su realización en forma de un vínculo interpersonal conyugal.

Según la hipótesis de ambos films el amor homosexual no sería otro sino el mismo amor. Aunque los sujetos no reprodujeran el binarismo sexo/género y el vínculo erótico heterosexual, el amor romántico como sentimiento $\mathrm{y}$ fundamento de la relación entre dos seres humanos permanecería inalterable. El problema eran los límites y censuras que las normas sociales le imponían a las emociones y no los sentimientos de los sujetos.

Esas producciones del "destape" nacional no apostaron por una deconstrucción de la pareja sexual estable como ideal normativo ni a una experimentación con el lenguaje cinematográfico. Por el contario, buscaban presentar y legitimar a la homosexualidad como otra versión del amor y una elección antes que un destino. Los films mantenían el modelo del amor romántico y la forma melodramática como su más importante dispositivo pedagógico. Esas historias/histerias eran otras, en el sentido de una más como recalca, con ironía, la esposa de Roberto cuando le pregunta: “¿Andan bien? ¿Están haciendo terapia de pareja? ¿Van a tener hijos?”.

Al mismo tiempo y dada la identidad de género de los amantes, estas historias/histerias eran otras, en tanto diferentes. Aunque el amor fuera el mismo, las relaciones de pareja homo y heterosexual, al igual que los encuentros eróticos, se presentaban como distintas. Las producciones ponían en escena las dificultades sociales para establecer una práctica homosexual de carácter conyugal, homóloga a la pareja heterosexual, y las consecuencias de la falta de reconocimiento legal del vínculo y privación de derechos civiles. Los films, tan significativos, en el momento de su estreno, para varones homosexuales que se identificaban con los protagonistas, se acercaban y preanuncian los reclamos de los movimientos LGBT que comenzaban a organizar por esos años (Belucci, 2010).

Tanto en la obra de Dawi como de Ortiz de Zárate, los vínculos homoeróticos aparecían como más igualitarios y menos machistas que los heterosexuales. Ese 
amor que no osaba decir su nombre se presentaba como más acorde a la "naturaleza" masculina que su versión heterosexual. Aparentemente, las mujeres no sabían tratar a los varones, quienes sólo entre iguales, podían desarrollar sus capacidades afectivas y eróticas.

Ese argumento, propio de la dominación masculina, aparece en ambas producciones donde las esposas son (re)presentadas como mujeres aburridas, "histéricas", nerviosas, demandantes, que querían conversar y acosaban con preguntas a sus maridos. Los varones homosexuales sabían que ese no era el camino. "Si querés que hable, tenés que callarte" le explicaba Marcelo a la esposa de su amante.

\section{Entre mujeres}

Mientras que para los varones homosexuales, a condición de ajustarse al nuevo modelo "gay", masculino y sin afeminamientos, las producciones cinematográficas de los primeros años del gobierno democrático ofrecían una posibilidad de amor, para las mujeres la situación se presentaba un tanto distinta. Los amores lésbicos aparecían en películas que se enmarcaban dentro del cine carcelario de mujeres, un subgénero cinematográfico que reconoce algunos antecedentes en la producción nacional como Mujeres en sombra (Catrano Catrani, 1951) Deshonra (Daniel Tinayre, 1952) y Las procesadas (Enrique Carreras, 1975).

A diferencia de esas películas, las producciones del "destape" de los años 1980 presentan desnudos femeninos frontales y tenían un mayor tinte erótico. Atrapadas (1984) es el segundo largometraje de Aníbal di Salvo, un director con una importante trayectoria en el mundo del cine, donde trabajó junto a artistas como Hugo del Carril, Mario Soffici, Leopoldo Torre Nilsson, Lucas Demare, entre otros. La película cuenta la vida en la cárcel de un grupo de mujeres a partir de la lucha entre Susana (Camila Perissé), una reclusa que con la colaboración del personal policial organiza la venta de estupefacientes al interior del presidio, y Silvia (Leonor Benedetto), una nueva detenida que se rebela contra su autoridad. 
Correccional de mujeres (1986), de Emilio Vieyra, un director asociado con el cine clase B, narra la historia de Laura Regueira (Edda Bustamante), una joven injustamente acusada de la muerte de su amante que se opone a la autoridad de las reclusas más antiguas protegidas por las celadoras implicadas en el tráfico de drogas y la organización de redes de prostitución. Un año antes, en 1985, Vieyra dirigió Sucedió en el internado, una película donde la acción transcurre en un colegio de mujeres pupilas de la alta sociedad porteña y plena de escenas de sexo entre docentes y alumnas, consumo de drogas, abortos, y violaciones.

Las tres producciones comparten un conjunto de rasgos comunes que las hace, en cierto sentido, indistinguibles, especialmente aquellas que tienen por escenario la prisión. Todas ellas se presentan como relatos originados a partir de hechos reales. En Correccional de mujeres se introduce a cada una de las detenidas por medio de un fotograma donde aparece su rostro y, con tipografía y sonido de máquina de escribir, el nombre, la edad, el estado civil y el número de prontuario policial. En Sucedió en el internado, si bien se nos advierte que los hechos narrados son ficcionales, la película concluye como un documental contándonos que una de las protagonistas fue condenada a prisión, otra está prófuga de la justicia y una tercera, culpable de dos asesinatos, internada en un manicomio. Atrapadas termina de manera semejante, con sonido de máquina de escribir se imprime en la pantalla el siguiente texto que cuenta qué ocurrió con Silvia: "Regresó cinco minutos antes del cambio de guardia. Nunca se pudo comprobar su participación en la masacre del 28 de mayo de 1980. Salió en libertad condicional un año después...."

La inclusión de escenas de sexo lésbico y otras de extrema crueldad, como asesinatos y violaciones, reforzaba performativamente esa pretensión de los films de contar una "historia real". Las obras se inscribían en el subgénero carcelario y otros de sexploitation que construían a la lesbiana como perversa (Taccetta y Peña, 2008) y continuaban el lenguaje "soft porno", presente de manera emblemática en las producciones de Armando Bo e Isabel Sarli. Al mismo tiempo que exponían relaciones de opresión, totalitarismo y violencia que se vivían en instituciones totales como la cárcel o la escuela de pupilas, la corrupción de policías y jueces, el tráfico de estupefacientes, el mundo del 
hampa, la vida disoluta de las clases altas, esas producciones buscaban lubrificar las fantasías eróticas de los espectadores.

Otro rasgo compartido es la presentación de las mujeres como vengadoras, salvajes, crueles, dominadas por sus pasiones. En las tres películas las protagonistas principales hacen justicia por mano propia. En Atrapadas, Silvia acaba asesinando a todos los que la maltrataron; en Correccional de mujeres, Laura con la ayuda de otras presidiarias con quienes escapó, voló por los aires la oficina donde estaban reunidos los jefes del narcotráfico y la madame que regenteaba una red de prostitución. En Sucedió en el internado, las estudiantes golpean con sus palos de hockey y reducen a un grupo de jóvenes que violaron a una profesora para finalmente colocarles brasas ardientes en los genitales. Otra característica común es la presencia de personajes femeninos hombrunos que usan su posición hegemónica, especialmente en el caso de las celadoras, para aprovecharse de jóvenes inocentes a las que corrompen a partir de las drogas y el sexo.

Estas producciones fueron calificadas como "prohibidas para menores de 18 años”. En la capital cordobesa se proyectaron en salas poco recomendables para "la familia" donde se exhibían películas de acción, producciones con contenido erótico, y otras como Adiós, Roberto y Otra historia de amor. A esas salas concurría preferentemente un público masculino formado por jóvenes estudiantes universitarios, conscriptos, miembros de las clases trabajadoras, y otros varones adultos en búsqueda de posibles encuentros homoeróticos.

La homosexualidad masculina también aparece brevemente en esas películas. Pero a diferencia de las producciones de Dawi y Ortiz de Zárate, aquí son los viejos modelos de la loca y el homosexual perverso, corruptor de menores, los que se ponen en escena. En Correccional de mujeres el carácter criminal del jefe de la organización mafiosa que dirige el tráfico de estupefacientes y personas aparece asociado con la impotencia masculina y se complementa con la práctica del voyerismo y el gusto por muchachos jóvenes y bien formados. En Sucedió en el internado vemos a un grupo de varones homosexuales, "locas", durante una cena de la alta sociedad que mantiene el siguiente diálogo: “¿Lo conocés?”, dice uno de ellos a un amigo cuando presenta al joven buen mozo que lo acompaña. 
“Cómo no lo voy a conocer", le responde el otro, "si fue sobrino mío el año pasado”. Esa pequeña escena que poco aporta al argumento resultaba humorística para quienes compartían los códigos de comunicación de esas locas. El guiño se basaba en el uso del término sobrino para designar a un amante más joven al cual, generalmente, se lo “ayudaba” económicamente.

\section{Sexo lésbico}

En el contexto carcelario marcado por la prostitución, el narcotráfico y la corrupción político-policial que presentan las películas, las mujeres aparecen como viciosas, malvadas, perversas, con una sexualidad polimorfa. Ellas son capaces de enredarse en relaciones lésbicas dada la falta de varones $\mathrm{u}$ obedeciendo a un deseo promiscuo y manipulador que les sería "natural”.

Las caricias y besos lésbicos aparecen en los encuentros entre celadoras e internas donde las primeras, cubiertas con el uniforme del Estado, se presentan como activas y masculinas. Por ejemplo, en Correccional de mujeres, una de las detenidas, Alicia, es seducida apenas ingresa por la jefa de seguridad, quien advierte a las otras presas: “A esta no me la tocan”. En una escena posterior ella le ofrecerá protección a cambio de sexo y drogas.

Las escenas sexuales también se daban entre las presas. Por las noches, cuando todas se iban a dormir, algunas saltaban de cama y compartían con ardor el lecho. Otras veces los encuentros se daban en los baños, podían involucrar a varias mujeres y se asociaban con el consumo de marihuana y cocaína. En algunas ocasiones podían tener un carácter más lúdico como en una escena orgiástica de Correccional de mujeres, donde las detenidas se besaban y acariciaban mientras bailaban, reían y jugaban a ser reinas y tomar champagne.

Cabe destacar que no se muestran escenas de sexo entre las carceleras, marcando quizá cómo los comportamientos homosexuales se relacionaban con las "desviaciones" de algunas integrantes del cuerpo de celadoras pero no constituían una práctica habitual de la fuerza policial.

Antes que presentar historias de amor entre mujeres, los films de di Salvo y Vieyra, desplegaban planos medios y generales que dejaban ver mujeres 
semidesnudas, besándose en sus cuellos y senos, acariciándose apasionadamente en celdas, baños, vestuarios. También aparecían primeros planos de pechos turgentes y pezones erguidos, de caderas que se movían rítmicamente, piernas que se rozaban una y otra vez, y algún que otro beso. La iluminación barroca de muchas de las tomas reforzaba el carácter fragmentario de los cuerpos e imbuía a las caricias de un tono romántico y sórdido.

A esas escenas lúdicas se sumaban otras en las cuales mujeres luchaban cuerpo a cuerpo, se enfrentaban violentamente, y desgarrando sus vestiduras dejaban ver, otra vez, senos, pezones, entrepiernas, glúteos, pubis no depilados. Alternando primeros planos y planos generales, con sonido e iluminación ambiental, esas escenas teatralizaban la violencia y la cargaban de erotismo. Los cuerpos se volvían trozos de carne cuando se combinaba elementos propios del género "gore" como del "soft porno". Esa poética "gorno" también estructuraba las escenas de violaciones de mujeres por parte de varones, quienes raramente aparecían desnudos. En esos casos, la cámara elegía detenerse en los senos de las mujeres, sus piernas y rostros sufrientes así como en la expresión de placer perverso de los varones.

El cuerpo desnudo de las mujeres aparecía también en las escenas de sexo heterosexual consentido y en las escenas de revisación al ingreso a la cárcel construidas a partir de un repertorio de recursos propios del cine sexploitation. Por ejemplo, en los primeros minutos de Correccional de mujeres, cuando se narra el ingreso de las reclusas a la institución, se ve cómo las mujeres son obligadas a desvestirse y dejan ver sus prendas íntimas, pubis, senos. “¿Nos van a tomar una prueba para el cine?” dice una de las reclusas, mientras mueve su cuerpo como una bailarina erótica. La voz de una celadora fuera de escena le responde: "Le vamos a quitar la mugre”. A continuación, un plano general muestra una decena de mujeres desnudas que, bajo la mirada vigilante de las autoridades carcelarias, toman alegremente una ducha y se enjabonan unas a otras. La violencia y el abuso de las interacciones representadas se (in)visibilizaban y erotizaban tras el brillo húmedo de los cuerpos.

Los guiones sexuales ofrecidos para las relaciones lésbicas por esas producciones cinematográficas resultaban extremadamente pobres. El carácter 
unidimensional y la falta de profundidad en la construcción psicológica de los personajes obturaba cualquier tipo de construcción de guiones intrapsíquicos e interpersonales para el encuentro entre dos mujeres que se aman. Sólo la perversidad "natural” de las mujeres, el consumo de drogas o la falta de varones permitía explicar/justificar ese homoerotismo asociados con el crimen y la "mala vida". La homosexualidad no sería sino otro indicador más de la degeneración moral de esas mujeres.

Los films no ofrecían una interpretación destinada a construir "otra historia de amor” entre mujeres. La relación de pareja no aparecía como una opción posible para ellas, quienes sólo se enredaban en escarceos amorosos carentes de significación afectiva. Esa ausencia de guiones positivos para los amores lésbicos denuncia la identidad del espectador ideal que construían las producciones. La proliferación de desnudos femeninos, de caricias y besos lésbicos, y de relaciones heterosexuales donde casi no dejaba ver el cuerpo masculino, tenían por objetivo encender el erotismo de varones heterosexuales.

Excluidos de las pantallas, los guiones culturales de y para la homosexualidad femenina encontraron eco en el emergente "rock nacional” donde participaban jóvenes de camadas medias. En este otro "mundos de arte" (Becker, 2008), cuya producción no contaba con patrocinio estatal y dependía de su inserción en el mercado discográfico, artistas como Marilina Ross, Sandra Mihanovich y Celeste Carballo, propusieron, de maneras más o menos explícitas, formas de ser lesbiana ausentes en el cine. Ellas cuestionaban, con sus canciones y performances, la moral sexual, “occidental y cristiana”, defendida por la última dictadura. En su lugar, y como parte de la apertura democrática, proponían al amor erótico como el fundamento de la pareja sexual. Al igual que en las obras de Dawi y Ortiz de Zárate, ya no se trataba de respetar la monogamia o limitar las caricias de acuerdo a la identidad de género del amante. El amor, el "verdadero" amor, fluía más allá de toda frontera e implicaba una intensa experiencia de autoconocimiento según contaba la canción "Puerto Pollensa" de Marilina Ross, de gran difusión en la época. 


\section{8. ¿Continuará?}

Durante los años del "destape”, y aún sin nombrarlo, un par de films visibilizaron y "presentaron en sociedad”, con un lenguaje melodramático ya conocido, el nuevo guión "gay". Esas historias se encarnaban en varones masculinos de camadas medias, educados, cultos, amigables, trabajadores, buenos hijos y, en algunos casos, padres. Esas producciones, escasamente reseñadas por la crítica periodística de la época y rodeadas de algún escándalo, (re)presentaron una ruptura en la cinematografía nacional no tanto por el lenguaje audiovisual que pusieron en juego como por los temas que abordaron.

En un clima de efervescencia democrática, pero también de persecución y represión de la homosexualidad, los films de Dawi y Ortiz de Zárate ofrecían y legitimaban nuevos guiones posibles para las conductas sexuales y los sentimientos de algunos sujetos. La homosexualidad dejaba de ser una enfermedad o desviación moral para transformarse en una posibilidad erótica que debía afrontar y enfrentar, en nombre del amor, los prejuicios de una sociedad autoritaria que se definía como “occidental y cristiana”. De una forma un tanto caricaturesca, como un sainete, las películas retrataban esos prejuicios, los agentes encargados de mantenerlos (sacerdotes, corporaciones, compañeros de trabajos, la familia, los vecinos), denunciaban la homofobia y las prácticas de outing.

A diferencia de Adiós Roberto y su final abierto, Otra historia de amor se encargó de construir un "happy end”, donde la pareja homosexual era posible. Raúl no tomó el avión rumbo a España, renunció a su trabajo y eligió ser feliz junto a Jorge. Ese final fue censurado cuando, en la década siguiente, la película se proyectó por primera vez en la TV abierta. El canal recortó los últimos minutos de modo tal que los protagonistas no se reencontraban, (re)marcando, una vez más, como imposible al amor homosexual.

En un tiempo de "recuperación democrática", y financiadas con subsidios estatales, esas producciones establecían un cauce legible/legítimo para los deseos homosexuales a través de una conyugalidad mimética del matrimonio heterosexual. Por medio de un lenguaje melodramático proponían un modo "terapeútico" de resolver los conflictos, definidos como "psicológicos”, de 
aquellos que se enredaban en prácticas homoeróticas, y planteaban transformar la historia en histeria.

La proyección de esos guiones sexuales “gays" puso entre tinieblas prácticas y experiencias homoeróticas de sujetos de sectores populares, de adultos mayores, de "locas”, “chongos” y personas transexuales. Sólo ciertos amores y caricias homoeróticas, obedientes a la gramática de la clase y el género, gerontofóbicos, y ciscentrados, obtuvieron legibilidad y legitimidad.

Fuera de la amiga lesbiana que aparece en Adiós Roberto, las mujeres homosexuales de camadas medias, a diferencia de los varones de su misma clase y generación, no encontraron una imagen cinematográfica donde reconocerse. Las historias erótico-afectivas entre esas mujeres, presentes en el cine argentino anterior a la última dictadura en películas como Tres veces Ana (David Kohon, 1961) o Piedra libre dirigida por Leopoldo Torre Nilsson que se estrenó meses después del golpe de Estado de 1976, no formaron parte de los relatos que circulaban durante la "primavera alfonsinista".

Las lesbianas cinematográficas de di Salvo y Vieyra se asociaban con la "mala vida”, el lumpenproletariado, las clases adineradas, pero nunca con los valores de una "cultura del trabajo" y "de los afectos" propios de los sectores medios. Esas producciones, interesadas en (re)presentar según una estética "gorno" las caricias entre mujeres, reforzaban la “dominación masculina” (Bourdieu, 2000) y guiones sexuales, heterosexistas y lesbofóbicos. Fue en el mundo del rock local donde esas lesbianas, invisibilizadas por la cinematografía nacional, construyeron relatos de amores entre mujeres.

En los años siguientes al final de la última dictadura argentina disminuyó el desequilibrio de poder entre los sexos, a partir de la sanción de las leyes de patria potestad compartida y divorcio, la transformación de la sexualidad en materia de discusión pública, la (re)organización de grupos feministas y de activismo homosexual. Como parte de esa dinámica social, la industria cinematográfica presentó y permitió imaginar relaciones erótico-afectivas más allá de la norma heterosexual. Otras historias sentimentales aparecieron como posibles de ser contadas con financiamiento estatal y final feliz. Sin embargo, esos vínculos de amor homosexual se reservaron para varones de camadas 
medias, de edades semejantes, y con performances masculinas. A otros sujetos masculinos y a las lesbianas, independientemente de cualquier marcador de la desigualdad social, sólo se les propuso un sexo perverso y carente de afectos. Aunque cambiantes, los desequilibrios de poder se mantenían.

Las diferencias reseñadas muestran algunas de las tensiones que organizaban la moral sexual de la época y su distinta realización en mundos del arte específicos. Los films analizados (in)visibilizaron diferencialmente prácticas eróticas y afectividades homosexuales de acuerdo al género pero también a la posición de clase y edad de los amantes. Para ello, y sin proponer mayores innovaciones en el lenguaje cinematográfico, esas producciones utilizaron la forma melodramática para narrar las historias/histerias de algunos varones mientras representaron las caricias lésbicas bajo una estética "gorno".

Distintos guiones sexuales y formas de desigualdad social se realizaban al proyectar, con estilos y para públicos diferentes, los amores de 1@s rar@s. En esa dinámica, las mujeres no sólo no encontraron un guión para sus amores sino que, una vez más, sus prácticas homoeróticas se transformaron en un estímulo para la mirada masculina heterosexual. Los varones, tanto aquellos que podían reconocerse en las historias de amor "gay" como quienes se excitaban con el sexo lésbico, resultaron los principales beneficiados.

\section{Referencias bibliográficas}

Becker, H. (2008). Los mundos del arte. Sociología del trabajo artístico. Buenos Aires: Universidad Nacional de Quilmes.

Belucci, M. (2010). Orgullo. Carlos Jáuregui. Una biografía política. Buenos Aires: Emecé

Blázquez, G. (2008). Gays y gaises en los bailes de Cuarteto. Humor, homofobia y heterosexismo entre jóvenes de los sectores populares en argentina. Sexualidades: A Working Papers Series on Latin America and Caribbean Sexualities 1(1).

Blázquez, G. \& Lugones, M.G. (2014). Cositas fuera de lugar: Miradas oblicuas en y sobre una noche cordobesa de inicios de los 80. En Dora Barrancos, Donna Guy y Adriana Valobra (eds), Moraliddes y comportamientos sexuales. Argentina 1880-2011. Buenos Aires: Biblos.

Bourdieu, P. (2000). La dominación masculina. Barcelona: Anagrama. 
Gagnon, J. \& Simon, W. (1974). Sexual Conduct: The Social Source of Human Sexuality. Chicago: Aldine.

Gagnon, J. (1977). Human Sexualities. Illinois: Scott Foresman.

Geertz, C. (1987). La Interpretación de las Culturas. Barcelona: Gedisa.

Goffman, E. (1979). Ritual de la interacción. Buenos Aires: Tiempo Contemporáneo.

Jaúregui, C. (1987). La homosexualidad en la Argentina. Buenos Aires: Tarso.

Meccia, E. (2006). La cuestión gay. Buenos Aires: Gran Aldea.

Meccia, E. (2011). Los últimos homosexuales. Buenos Aires: Gran Aldea

Melo, A. (comp.) (2008). Otras historias de amor. Buenos Aires: Lea.

Olivera, G. (2012). Entre lo innombrable y lo enunciable: visibilidades e espacialidades LGBT en el cine argentino /1960-1991. En Forastelli, F \& Olivera, G (ed.), Estudios Queer. Semióticas y políticas de la sexualidad (pp.99-111). Buenos Aires: La Crujía.

Perlongher, N. (1997). Prosa plebeya Buenos Aires: Colihue.

Reches, A. (2014). Prácticas de sociabilidad festiva de varones homosexuales a inicios de la década de 1980 en la ciudad de Córdoba. Questión. Revista especializada en periodismo y comunicación, 1 (42), 376-391. http://perio.unlp.edu.ar/ojs/index.php/question/index.

Sívori, H. (2005). Locas, chongos y gays. Sociabilidad homosexual masculina durante la década de 1990. Buenos Aires: Antropofagia.

Taccetta, N. \& Peña, F. (2008). El amor de las muchachas. En Melo, A. (ed.), Otras historias de amor (pp. 115-132). Buenos Aires: Lea.

Turner, Victor. (1974). Dramas, Fields and Metaphors. Ithaca: Corner University Press.

Williams. L. (2008). Screening Sex. Durham: Duke University Press.

\section{Filmografía}

Campusano, J. (2008). Vil Romance. Argentina: Cinebruto.

Carreras, E. (1975). Las procesadas. Argentina: Sono Film.

Catrano, C. (1951). Mujeres en sombra. Argentina: Producciones Otto Lamm.

Dawi, E. (1985). Adiós Roberto. Argentina: Dawi producciones.

Di Salvo, A. (1984). Atrapadas. Buenos Aires: Luis A. Scalella \& Carlos Luis Mentasti Productores.

Kohon, D. ( 1961). Tres veces Ana. Argentina: Marcelo Simonetti.

Ortiz de Zárate, A. (1986). Otra historia de amor. Argentina: Juan Antonio Muruzeta Producciones cinematográficas.

Tinayre, D. ( 1952). Deshonra. Argentina: Mapol Film/ Interamericana. 
Torre Nilsson, L. (1976). Piedra libre dirigida. Argentina: MBC Producciones S.A.

Vieyra. E. (1985). Sucedió en el internado. Argentina: Fernando Molina

Vieyra. E. (1986). Correccional de mujeres. Argentina: Super Films / G.A.G. Productions. 